\title{
Effectiveness of the nutritional supplement used in the Mexican Oportunidades programme on growth, anaemia, morbidity and cognitive development in children aged 12-24 months
}

\author{
Jorge L Rosado ${ }^{1,2, *}$, Patricia López ${ }^{3}$, Olga P García ${ }^{1}$, Javier Alatorre ${ }^{4}$ and \\ Claudia Alvarado' \\ 'Department of Human Nutrition, School of Natural Sciences, Universidad Autónoma de Querétaro, Avenida \\ de las Ciencia S/N, Juriquilla, Querétaro, Mexico: ${ }^{2}$ CINDETEC, Jurica 122, Parque Industrial Querétaro, \\ Querétaro, 76220, Mexico: ${ }^{3}$ Department of Physiology, National Institute of Medical Sciences and Nutrition \\ 'Salvador Zubirán', Vasco de Quiroga 15, Col. Tlalpan, Mexico City, Mexico: ${ }^{4}$ Department of Psychology, \\ Universidad Nacional Autónoma de México, Mexico City, Mexico
}

Submitted 30 March 2010: Accepted 14 October 2010: First published online 21 December 2010

\begin{abstract}
Objective: To determine the effectiveness of the nutritional supplement developed for the Oportunidades programme on growth, prevalence of anaemia, morbidity and cognitive function of pre-school children.

Design: In a randomised, placebo-controlled longitudinal trial, children were assigned to one of three experimental treatment groups: Oportunidades food supplement (OFS), powdered milk (PM) and placebo (PL). Treatments were administered daily for 6 months. Weight, height and $\mathrm{Hb}$ were measured in all participants before and after supplementation. Morbidity was assessed two times per week for 6 months using validated questionnaires. The Bayley Scale of Infant Development Test was administered at baseline and after 6 months.

Setting: Three marginal rural communities of the state of Queretaro, Mexico.

Subjects: A total of 224 children, mean age 22.4 (SD 5.9) months, were recruited. After the 6-month intervention, 186 completed the study.

Results: No differences were found in the adjusted changes of weight, height or anaemia between treatment groups and PL. No differences were found in the number of episodes of gastrointestinal or respiratory disease, nor were there any differences in cognitive performance between treatment and PL groups after 6 months of supplementation.

Conclusions: Daily supplementation of 12-24-month-old children with OFS has no additional benefits in growth, anaemia, morbidity or cognitive performance.
\end{abstract}

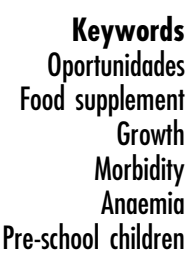

The Oportunidades programme (previously called PROGRESA) is a federal government programme that was launched in Mexico in 1997. The main objective of the Oportunidades programme is to alleviate poverty and its consequences through three main components: nutrition, health and education. Target households are those living in underprivileged communities and with a low socioeconomic status $^{(1)}$. The programme includes conditional cash transfers, obligatory attendance to preventive and curative health services and the monthly distribution of a food supplement. The nutritional supplement is a milkbased product targeted at children aged 6-23 months, children aged 2-4 years with weight-for-height $<1$ SD, as well as at pregnant and lactating women. The food supplement targeted at 6-23-month-old children is locally called 'papilla' (porridge), with its design initially considered as an amount of supplemental energy of about
$703 \mathrm{~kJ}(168 \mathrm{kcal})$ and the recommended amount of most vitamins and minerals at that time ${ }^{(2)}$. The effectiveness of the supplement on functional outcomes has not been prospectively evaluated in controlled studies.

Some studies have evaluated the effects of the Oportunidades programme on children's growth and on the prevalence of anaemia in both rural and urban populations $^{(3,4)}$. Additional findings have been reported by the National Institute of Public Health ${ }^{(5-7)}$. These studies evaluated the impact of the programme, and hence the effect of the supplement cannot be derived from them. In addition, no studies have been carried out that evaluate the effect of the nutritional supplement on morbidity and cognitive development.

We conducted a randomised, placebo-controlled, longitudinal trial to evaluate the effect of the food supplement on growth, anaemia, morbidity and cognitive function. 


\section{Experimental methods}

\section{Subjects and place of study}

The study was carried out in three marginal rural communities in Queretaro, Mexico, in populations that have been selected for the Oportunidades programme, but had not been included at the time of the study. Children were not included if they had participated in any other food-related programme. The purpose of the study was explained to the parents of all non-breast-feeding children between 12 and 24 months of age at each of the communities. Only those children whose parents agreed to participate voluntarily and signed an informed consent form were included in the study. The study protocol was approved by the Ethics Committee of the National Institute of Medical Sciences and Nutrition 'Salvador Zubirán' and by the Ethics Committee of University of Queretaro.

The sample size was determined considering a minimum expected difference of $0.8 \mathrm{~cm}$ in growth between treatment and PL, an SD of $1.5 \mathrm{~cm}$ in change of height, an alpha error of $5 \%$, a beta error of $20 \%$ and a dropout rate of $30 \%$. We calculated that 222 children (74 per group) was an adequate sample size for the study.

\section{Study design}

The study was a randomised, placebo-controlled longitudinal trial. Parents of all children who agreed to participate in the study were asked to bring their child to the health clinic of each community. A total of 224 children were stratified by height-for-age $Z$-score (HAZ) and assigned to one of the three experimental groups. One group of children received a daily dose of $44 \mathrm{~g}$ of the nutritional supplement that was designed for the Oportunidades programme (OFS; $n$ 74). This is the amount of supplement recommended. A second group of children received a daily dose of $25 \mathrm{mg}$ of whole powdered milk (PM; $n$ 75). This is the amount of milk in one glass at regular density. A third group of children received $44 \mathrm{~g}$ of a placebo in a powdered form (PL; $n$ 75). All supplements were administered for 6 months. Mothers were asked not to modify the children's regular meals and food for the duration of the study.

Children in the three groups started receiving the treatments from the next day after baseline measurements at the health clinic. Supplements were given daily in a coded, aluminium-foil sachet containing a daily dose of premeasured powder of the corresponding treatment. Codes were sealed to all study personnel and participants. The nutrient composition of the different treatments is described in Table 1. OFS had a significantly higher content of carbohydrates and micronutrients, including Fe and $\mathrm{Zn}$, than did the PM. The PL contained no protein, only carbohydrates in the form of maltodextrin. The nutrient composition of all supplements was analysed following standard methods as described previously ${ }^{(8)}$. The identification of codes for the supplements was revealed to the principal investigator and statistician only after data analysis had been completed.
Table 1 Nutrient composition of the three supplements administered to children for 6-month treatments: OFS, PM and PL

\begin{tabular}{|c|c|c|c|}
\hline Nutrients & $\begin{array}{c}\text { OFSt } \\
\text { (44 g/serving) }\end{array}$ & $\begin{array}{c}\text { PMł } \\
\text { (25 g/serving) }\end{array}$ & $\begin{array}{c}\text { PL§ } \\
\text { (44 g/serving) }\end{array}$ \\
\hline Energy (kcal) & 194 & 123 & 174 \\
\hline Energy (kJ) & $814 \cdot 8$ & $516 \cdot 6$ & $731 \cdot 6$ \\
\hline Proteins $(g)$ & $5 \cdot 8$ & $6 \cdot 4$ & 0 \\
\hline Fat $(g)$ & $6 \cdot 6$ & $6 \cdot 5$ & 0 \\
\hline Carbohydrates (g) & $27 \cdot 9$ & $9 \cdot 8$ & $30 \cdot 8$ \\
\hline $\mathrm{Na}(\mathrm{mg})$ & $24 \cdot 5$ & 86 & 0 \\
\hline $\mathrm{Fe}(\mathrm{mg})$ & 10 & 0.07 & 0 \\
\hline Zn (mg) & 10 & $0 \cdot 7$ & 0 \\
\hline Vitamin A ( $\mu \mathrm{g})$ & 400 & 162 & 0 \\
\hline Vitamin E (mg) & 6 & $0 \cdot 1$ & 0 \\
\hline Vitamin C (mg) & 40 & $1 \cdot 7$ & 0 \\
\hline Vitamin $B_{12}(\mu \mathrm{g})$ & 0.7 & $0 \cdot 7$ & 0 \\
\hline Folic acid $(\mu \mathrm{g})$ & 50 & $10 \cdot 2$ & 0 \\
\hline Riboflavin (mg) & $0 \cdot 8$ & $1 \cdot 9$ & 0 \\
\hline
\end{tabular}

OFS, Oportunidades food supplement; PM, powdered milk; PL, placebo. tComposition according to Rosado et al. ${ }^{(2)}$.

‡Composition of low-fat PM by analysis.

$\S$ Composition in accordance with specifications and analysis.

The children's mother or caregiver was responsible for the preparation and administration of the supplement. On the first day, fieldworkers explained in detail how to prepare the treatments. The OFS was prepared by dissolving the premeasured content of the sachets in $25 \mathrm{ml}$ of boiled water, and mixing until a homogeneous porridge was formed. The PM and PL were prepared by diluting the pre-measured content of the sachets in 180 and $25 \mathrm{ml}$ of boiled water, respectively. The treatments were provided by trained fieldworkers to the children at their homes, every day for 6 months. The fieldworker was responsible for the delivery and supervision of the treatments. If the supplements were not consumed, the fieldworker had to register the date and the reason. During the visits, fieldworkers asked the mothers whether they had any questions regarding the preparation of the supplement to ensure that all supplements were prepared according to instructions.

During the first visit to the health clinic, the child's weight and height were measured and a baseline fasting blood sample was taken to determine $\mathrm{Hb}$. Weight and height measures were repeated at 3 and 6 months after the commencement of treatment. A second venous blood sample was collected after 6 months of treatment. Morbidity of the children was recorded two times per week in the three groups by fieldworkers during the 6 months of the study using a questionnaire that had been previously used with the same population ${ }^{(9)}$. Mothers were also asked to respond to a questionnaire to determine their socio-economic status. The children's cognitive performance was evaluated by trained psychologists before supplementation and the same tests were repeated 6 months after supplementation.

\section{Weight, beight and $\mathrm{Hb}$ measurements}

Weight and height measurements in every child were taken by the same examiner at the health centres of their communities following standard procedures ${ }^{(10)}$. Children 
were weighed to the nearest $1 \mathrm{~g}$ without sweater or jacket and without shoes using an electronic paediatric scale (SECA, Hamburg, Germany). Height was assessed to the nearest $0 \cdot 1 \mathrm{~cm}$ using portable infantometers (SECA).

$\mathrm{Hb}$ concentration was measured in a drop of venous blood using a HemoCue (HemoCue Inc., Mission Viejo, CA, USA). The cut-off value to determine anaemia adjusted for altitude was an $\mathrm{Hb}$ concentration of $<11 \cdot 7 \mathrm{~g} / \mathrm{dl}^{(11,12)}$.

\section{Morbidity evaluation}

Morbidity was assessed two times per week during the 6-month duration of the study using previously validated questionnaires $^{(9)}$. The questionnaire was answered by the mothers and they reported whether the child had been sick on the day of the visit or $2 \mathrm{~d}$ before, as well as the date the event started, signs and symptoms associated with the disease, complications and the date the event ended. An episode was recorded by a trained fieldworker on a precoded list that included the most common signs and symptoms in this age group. Gastrointestinal disease was determined if the mother reported more than three liquid stools or one liquid stool with blood. Respiratory disease was determined if the mother reported sore throat, flu or cough. The number of episodes of gastrointestinal infections or respiratory infections was the outcome variable for the morbidity analysis.

\section{Cognitive and motor performance evaluation}

An evaluation of cognitive and motor functions was carried out by trained psychologists. The Bayley Scale for Infant Development (BSID-II) was applied to evaluate mental and motor abilities ${ }^{(13)}$. The Motor Bayley scale has 111 items that evaluate both gross and fine motor areas, from which, according to each child's age, an average of 16.8 (SD 1.2) items were administered. The evaluated abilities are body control, big muscle group control associated with crawling, sitting, standing, walking, running and jumping, hand and finger manipulation and psychomotor skills and coordination. This scale provides a Psychomotor Development Index. The mental scale has 178 items that evaluate sensory-perceptual acuity, sequences, memory, learning, problem solving, socialisation and language. The average number of items administered in the study population was $29 \cdot 4$ (SD 3.2). This scale provides a Mental Development Index. The tests were applied at the beginning of the study and the same tests were applied after 6 months of supplementation. Each child was evaluated by the same psychologist.

\section{Data analysis}

$Z$-scores of height-for-age, weight-for-age and weight-forheight were determined using the growth references of $\mathrm{WHO}^{(14)}$. Cognition variables that did not fit the normal distribution were log-transformed to fulfil assumptions required by the statistical tests; other variables did not need transformation. Two sets of ANOVA were performed to compare the changes (final and initial) between treatments, unadjusted analysis and adjusted analysis for initial value, age and community random effect. The analysis of cognition variables was adjusted for age, mother's education level and the school random effect. Chi-square tests were performed to measure associations between allocated treatment and a categorical response variable. Statistical analyses were performed using the Statistical Package for the Social Sciences statistical software package version $10 \cdot 0$ (SPSS Inc., Chicago, IL, USA).

\section{Results}

Of the 224 children included in the study, 186 finished the 6-month treatments (Fig. 1). The characteristics of the twelve children who refused to participate did not differ from those of the sample. Thirty-seven children were lost to follow-up because of lack of compliance, and one child did not show up for the initial evaluation. Children who were lost to follow-up did not differ from children who remained with respect to age, gender and community. No differences were found in weight or height measurements at baseline between the thirty-seven children who did not finish the study and the children who did complete the study.

Characteristics of participants in the experimental groups at the beginning of the study are shown in Table 2 . The mean age of the children was $22 \cdot 5$ (sD 5.8), $22 \cdot 8$ (sD 6.1) and $22 \cdot 7$ (SD 5.6) months for the OFS, PM and PL groups, respectively. Approximately $43 \%$ of the children were anaemic and $17 \%$ were stunted. No differences were found between groups at baseline in any of the study variables.

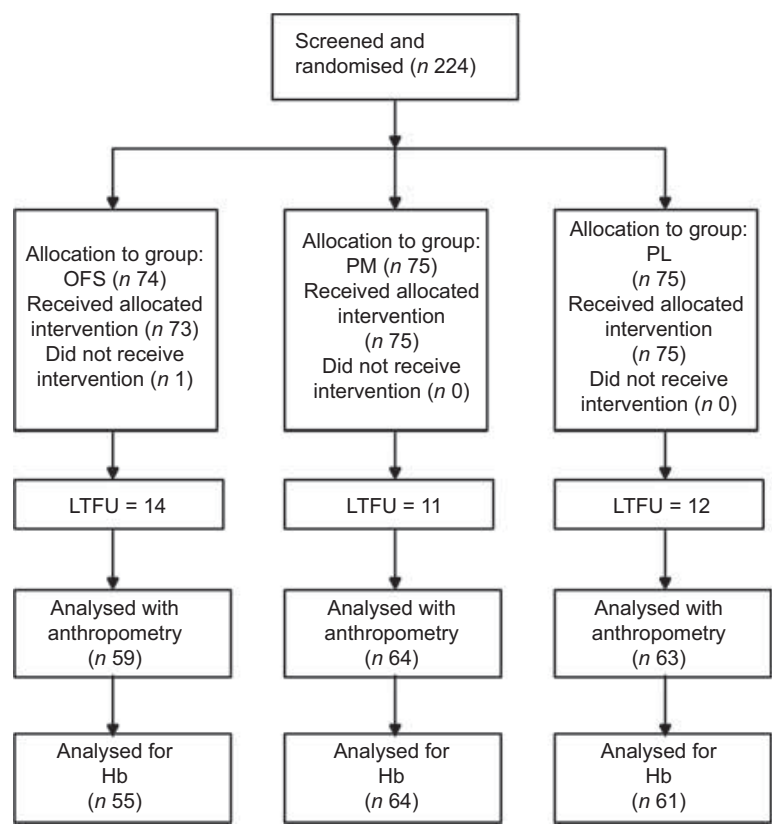

Fig. 1 Trial profile (OFS, Oportunidades food supplement; PM, powdered milk; PL, placebo; LTFU, lost to follow-up) 
Treatment adherence was high and similar in all three groups: $92 \%$ in the OFS group, $93 \%$ in the PM group and $90 \%$ in the PL group. Change in weight was significant

Table 2 Characteristics of participants at baseline in the three groups receiving different supplements: OFS, PM and PL

\begin{tabular}{|c|c|c|c|}
\hline & $\begin{array}{c}\text { OFS } \\
(n 59)\end{array}$ & $\begin{array}{c}\mathrm{PM} \\
(n 64)\end{array}$ & $\begin{array}{c}\mathrm{PL} \\
(n \text { 63) }\end{array}$ \\
\hline Characteristics & $\%$ & $\%$ & $\%$ \\
\hline Boys & $54 \cdot 2$ & $58 \cdot 5$ & $58 \cdot 5$ \\
\hline Height-for-age (Z-score $<2 \mathrm{sD})$ & $20 \cdot 3$ & $12 \cdot 7$ & $19 \cdot 0$ \\
\hline Weight-for-age (Z-score < 2 sD) & $5 \cdot 4$ & $5 \cdot 0$ & $7 \cdot 9$ \\
\hline Weight-for-height (Z-score $<2 \mathrm{SD}$ ) & $0 \cdot 0$ & $5 \cdot 0$ & $3 \cdot 2$ \\
\hline BMI-for-age ( $Z$-score $<2 \mathrm{sD})$ & $0 \cdot 0$ & $3 \cdot 3$ & $1 \cdot 6$ \\
\hline Anaemic & $41 \cdot 9$ & $44 \cdot 6$ & $44 \cdot 6$ \\
\hline
\end{tabular}

OFS, Oportunidades food supplement; PM, powdered milk; PL, placebo. Non-significant $\chi^{2}$ test. only in the groups receiving OFS and PM $(P<0 \cdot 01$; Table 3). Change in BMI and height was significant in the three experimental groups $(P<0 \cdot 01)$. Final HAZ was significantly higher compared with baseline only in the group receiving OFS $(P<0 \cdot 05)$. However, there were no differences in weight or height evaluation (adjusted and unadjusted) between groups after 6 months of treatment. Prevalence of stunting at the end of the study was $17 \%$ for the OFS, 5\% for the PM and 16\% for the PL groups. No significant effect of treatment was found after 6 months in the prevalence of stunting after adjusting for initial values in the OFS or PM group compared with PL.

At the beginning of the study, the prevalence of anaemia was high in all treatment groups (43\%), and was not significantly different. All the experimental groups showed a decrease of about $50 \%$ in the prevalence of anaemia at the end of the study. Rates of final prevalence of anaemia

Table 3 Weight, height and $\mathrm{Hb}$ concentration of children before and after 6 months of supplementation with the OFS, PM and PL

\begin{tabular}{|c|c|c|c|c|c|c|c|c|}
\hline & & OFS & & & & & PL & \\
\hline & Mean & & SD & Mean & SD & Mean & & SD \\
\hline $\mathrm{Hb}(\mathrm{g} / \mathrm{dl})$ & & $(n 55)$ & & & & & $(n 61)$ & \\
\hline Baseline & $11 \cdot 7$ & & $1 \cdot 7$ & $11 \cdot 8$ & $1 \cdot 6$ & $12 \cdot 0$ & & $1 \cdot 4$ \\
\hline After 6 months & $12 \cdot 4^{\star *}$ & & $1 \cdot 4$ & $12 \cdot 3^{\star \star}$ & $1 \cdot 4$ & $12 \cdot 2$ & & $1 \cdot 2$ \\
\hline Change & $0 \cdot 7$ & & $1 \cdot 4$ & 0.5 & $1 \cdot 2$ & $0 \cdot 2$ & & $1 \cdot 5$ \\
\hline Adjusted changet & $0 \cdot 6$ & & $1 \cdot 1$ & 0.5 & $1 \cdot 1$ & 0.4 & & $1 \cdot 1$ \\
\hline Weight (kg) & & $(n 57)$ & & & & & $(n 63)$ & \\
\hline Baseline & $10 \cdot 5$ & & $1 \cdot 6$ & $11 \cdot 1$ & $1 \cdot 6$ & $10 \cdot 7$ & & $1 \cdot 7$ \\
\hline After 6 months & $12 \cdot 1^{\star *}$ & & $1 \cdot 7$ & $12 \cdot 8^{\star \star}$ & $1 \cdot 6$ & $12 \cdot 2$ & & $1 \cdot 9$ \\
\hline Change & $1 \cdot 5$ & & $0 \cdot 5$ & $1 \cdot 7$ & $0 \cdot 8$ & $0 \cdot 8^{* *}$ & & $0 \cdot 8$ \\
\hline Adjusted changet & $1 \cdot 5$ & & $0 \cdot 7$ & $1 \cdot 7$ & $0 \cdot 7$ & $1 \cdot 5$ & & $0 \cdot 7$ \\
\hline Height $(\mathrm{cm})$ & & $(n 60)$ & & & & & $(n$ 62) & \\
\hline Baseline & $81 \cdot 2$ & & $5 \cdot 7$ & $83 \cdot 0$ & $5 \cdot 8$ & $82 \cdot 2$ & & $5 \cdot 9$ \\
\hline After 6 months & $87 \cdot 8^{\star *}$ & & $5 \cdot 3$ & $89 \cdot 5^{\star \star}$ & $5 \cdot 2$ & $5 \cdot 8^{\star *}$ & & $5 \cdot 8$ \\
\hline Change & $6 \cdot 6$ & & $1 \cdot 7$ & $6 \cdot 5$ & $1 \cdot 5$ & $6 \cdot 2$ & & $1 \cdot 6$ \\
\hline Adjusted changet & $6 \cdot 5$ & & 1.5 & $6 \cdot 6$ & $1 \cdot 5$ & $6 \cdot 2$ & & 1.5 \\
\hline BMI $\left(\mathrm{kg} / \mathrm{m}^{2}\right)$ & & $(n 57)$ & & & & & $(n 63)$ & \\
\hline Baseline & $15 \cdot 9$ & & $1 \cdot 2$ & $15 \cdot 9$ & $1 \cdot 4$ & $15 \cdot 8$ & & $1 \cdot 0$ \\
\hline After 6 months & $15 \cdot 7^{\star \star}$ & & $1 \cdot 1$ & $15 \cdot 8^{\star \star}$ & $1 \cdot 2$ & $15 \cdot 6^{\star *}$ & & $1 \cdot 2$ \\
\hline Change & $-0 \cdot 3$ & & $0 \cdot 8$ & $-0 \cdot 1$ & $1 \cdot 0$ & $-0 \cdot 2$ & & $1 \cdot 0$ \\
\hline Adjusted changet & -0.3 & & 0.9 & $-0 \cdot 1$ & 0.9 & -0.2 & & 0.9 \\
\hline Height-for-age (Z-score) & & $(n 59)$ & & & & & $(n 62)$ & \\
\hline Baseline & $-1 \cdot 2$ & & $1 \cdot 0$ & -0.8 & $1 \cdot 0$ & $-1 \cdot 2$ & & $1 \cdot 0$ \\
\hline After 6 months & $-1 \cdot 1^{*}$ & & $1 \cdot 0$ & $-0 \cdot 7$ & $0 \cdot 8$ & $-1 \cdot 0$ & & $1 \cdot 1$ \\
\hline Change & 0.5 & & 0.5 & $-0 \cdot 1$ & 0.5 & $-0 \cdot 2$ & & $0 \cdot 7$ \\
\hline Adjusted changet & $0 \cdot 1$ & & $0 \cdot 6$ & $0 \cdot 1$ & $0 \cdot 6$ & $0 \cdot 1$ & & $0 \cdot 6$ \\
\hline Weight-for-age (Z-score) & & $(n 56)$ & & & & & $(n 62)$ & \\
\hline Baseline & $-0 \cdot 7$ & & 0.9 & -0.5 & 0.9 & -0.8 & & 0.9 \\
\hline After 6 months & $-0 \cdot 7$ & & 0.9 & $-0 \cdot 3^{*}$ & $0 \cdot 8$ & $-0 \cdot 7$ & & $1 \cdot 0$ \\
\hline Change & 0.0 & & $0 \cdot 4$ & $0 \cdot 2$ & $0 \cdot 6$ & $0 \cdot 1$ & & $0 \cdot 6$ \\
\hline Adjusted changet & $0 \cdot 0$ & & 0.5 & $0 \cdot 2$ & 0.5 & $0 \cdot 1$ & & 0.5 \\
\hline Weight-for-height (Z-score) & & $(n 57)$ & & & & & $(n 62)$ & \\
\hline Baseline & -0.2 & & 0.9 & $-0 \cdot 1$ & $1 \cdot 0$ & $-0 \cdot 3$ & & $0 \cdot 9$ \\
\hline After 6 months & $-0 \cdot 1$ & & $0 \cdot 8$ & $0 \cdot 1^{*}$ & $0 \cdot 9$ & $-0 \cdot 2$ & & 0.9 \\
\hline Change & 0.0 & & 0.6 & $0 \cdot 2$ & $0 \cdot 8$ & $0 \cdot 1$ & & $0 \cdot 8$ \\
\hline Adjusted changet & $0 \cdot 0$ & & $0 \cdot 6$ & 0.2 & $0 \cdot 6$ & $0 \cdot 1$ & & $0 \cdot 6$ \\
\hline BMI-for-age (Z-score) & & $(n 57)$ & & & & & $(n 62)$ & \\
\hline Baseline & $0 \cdot 1$ & & 0.9 & $-0 \cdot 0$ & $1 \cdot 1$ & $-0 \cdot 1$ & & 0.9 \\
\hline After 6 months & $0 \cdot 0$ & & 0.9 & $0 \cdot 2$ & $1 \cdot 0$ & $-0 \cdot 1$ & & $0 \cdot 9$ \\
\hline Change & $0 \cdot 0$ & & $0 \cdot 7$ & 0.2 & $0 \cdot 8$ & $0 \cdot 1$ & & $0 \cdot 8$ \\
\hline Adjusted changet & $0 \cdot 0$ & & $0 \cdot 7$ & $0 \cdot 2$ & $0 \cdot 7$ & $0 \cdot 0$ & & $0 \cdot 7$ \\
\hline
\end{tabular}

OFS, Oportunidades food supplement; PM, powdered milk; PL, placebo.

Post-treatment mean value is different from the initial value at ${ }^{\star} P<0.05$ or ${ }^{\star \star} P<0.01$.

tChange adjusted for initial value, age and the community random effect.

There were no significant differences between changes and adjusted changes in the three treatment groups. 
Table 4 Gastrointestinal and respiratory infections of children supplemented for 6 months with three different supplements: OFS, PM and PL†

\begin{tabular}{|c|c|c|c|c|c|c|}
\hline & \multicolumn{2}{|c|}{ OFS $(n 45)$} & \multicolumn{2}{|c|}{$\mathrm{PM}(n 50)$} & \multicolumn{2}{|c|}{$\mathrm{PL}(n 51)$} \\
\hline & Mean & SD & Mean & SD & Mean & SD \\
\hline Number of episodes of gastrointestinal infections & $1 \cdot 0$ & $1 \cdot 4$ & $1 \cdot 2$ & $1 \cdot 4$ & 0.9 & $1 \cdot 4$ \\
\hline Number of episodes of respiratory infections & $3 \cdot 8$ & $2 \cdot 5$ & $3 \cdot 1$ & $2 \cdot 5$ & $3 \cdot 1$ & $2 \cdot 5$ \\
\hline Duration of episodes of gastrointestinal infections (d) & $2 \cdot 2^{*}$ & $1 \cdot 5^{\star}$ & $1 \cdot 6$ & $1 \cdot 5$ & $1 \cdot 3$ & 1.5 \\
\hline Duration of episodes of respiratory infections (d) & $4 \cdot 1$ & $2 \cdot 5$ & $3 \cdot 6$ & $2 \cdot 5$ & $3 \cdot 4$ & $2 \cdot 5$ \\
\hline
\end{tabular}

OFS, Oportunidades food supplement; PM, powdered milk; PL, placebo.

${ }^{*}$ Significant difference compared with $\mathrm{PL}$ at $P<0.05$.

+ Values are means and SD adjusted for the number of days observed.

Table 5 Bayley Scale of Infant Development Test scores before and after 6 months of supplementation with three different supplements: OFS, PM and PL

\begin{tabular}{|c|c|c|c|c|c|c|}
\hline \multirow[b]{2}{*}{ Cognition tests } & \multicolumn{2}{|c|}{ OFS $(n 58)$} & \multicolumn{2}{|c|}{$\mathrm{PM}(n 65)$} & \multicolumn{2}{|c|}{$\mathrm{PL}(n 60)$} \\
\hline & Mean & SD & Mean & SD & Mean & SD \\
\hline \multicolumn{7}{|c|}{ Mental development (score) } \\
\hline Baseline & $117 \cdot 2$ & $16 \cdot 6$ & $118 \cdot 7$ & $18 \cdot 3$ & $118 \cdot 2$ & $16 \cdot 3$ \\
\hline After 6 months & $135 \cdot 9$ & $13 \cdot 7$ & $138 \cdot 3$ & $13 \cdot 6$ & $137 \cdot 6$ & $12 \cdot 6$ \\
\hline Change & $18 \cdot 7^{\star *}$ & $5 \cdot 9$ & $19 \cdot 6^{\star \star}$ & $7 \cdot 5$ & $19 \cdot 4^{\star \star}$ & $6 \cdot 6$ \\
\hline Adjusted changet & $18 \cdot 8$ & $4 \cdot 5$ & $20 \cdot 1$ & $4 \cdot 6$ & $19 \cdot 7$ & $4 \cdot 6$ \\
\hline \multicolumn{7}{|c|}{ Motor development (score) } \\
\hline Baseline & $78 \cdot 4$ & $8 \cdot 9$ & $79 \cdot 4$ & $9 \cdot 1$ & $78 \cdot 9$ & $8 \cdot 2$ \\
\hline After 6 months & $88 \cdot 6$ & $9 \cdot 2$ & $89 \cdot 6$ & $9 \cdot 2$ & $90 \cdot 0$ & $9 \cdot 3$ \\
\hline Change & $10 \cdot 2^{\star \star}$ & $3 \cdot 3$ & $10 \cdot 2^{\star \star}$ & $3 \cdot 5$ & $11 \cdot 1^{\star \star}$ & $3 \cdot 9$ \\
\hline Adjusted changet & $10 \cdot 3$ & $2 \cdot 9$ & $10 \cdot 4$ & $2 \cdot 9$ & $11 \cdot 1$ & $2 \cdot 9$ \\
\hline
\end{tabular}

OFS, Oportunidades food supplement; PM, powdered milk; PL, placebo.

Post-treatment mean value is different from the initial value at ${ }^{\star} P<0.05$ or ${ }^{\star \star} P<0.01$.

tChange adjusted for mother's education level, age, initial test result and community random effect.

There were no significant differences between changes and adjusted changes in the three treatment groups.

for the OFS, PM and PL groups were 20\%, 22\% and $20 \%$, respectively. The concentration of $\mathrm{Hb}$ increased significantly compared with baseline only in the groups receiving OFS or PM $(P<0 \cdot 05)$; however, after 6 months, $\mathrm{Hb}$ concentrations were not significantly different from that of the control group. Considering that the milk treatment had a lower prevalence of stunting and might have influenced the efficacy of the treatment, additional analyses adjusting for HAZ were performed and showed the same results for anthropometry and biochemical changes. In addition, another set of analyses that considered only stunted or anaemic children did not show a greater improvement of outcome variables in any treatment.

We found an average of one episode of gastrointestinal disease and $3 \cdot 3$ episodes of respiratory disease in this population during the 6 months of observation (Table 4). No significant differences were found between groups in the number of episodes of gastrointestinal infections and in the number and duration of respiratory infections. The duration of gastrointestinal episodes was significantly higher in the OFS group compared with the control group $(P<0 \cdot 05)$.

Children had an increase in their mental and motor development in all groups at the end of the study in accordance with the Bayley Scale results; however, the changes were similar among the three experimental groups (Table 5).

\section{Discussion}

In a longitudinal evaluation of the effect of the nutritional supplement used in the Oportunidades programme in Mexico, we did not find an additional benefit from intake of the supplement during the 6-month period on growth, prevalence of anaemia, morbidity or cognitive performance on children aged 12-24 months, compared with supplementing with milk or a PL containing only carbohydrates. Comparison of our findings with previous studies is limited because these studies have mainly evaluated the effect of the programme as a whole, including the effect of the supplement intake with other parts of the programme such as education and health care. Nevertheless, in the analysis of previous evaluations, some interesting conclusions can be derived.

In a randomised, controlled intervention study, Rivera et $a l^{(3)}$ did not find an effect of the Oportunidades programme on the growth of children between 6 and 24 months of age. In this same study, height was significantly greater by $1 \cdot 1 \mathrm{~cm}$ among the younger ( $<6$ months of age) and poorest children compared with children not included in the programme $(26.4 \mathrm{~cm}$ in the Oportunidades group $v .25 \cdot 3 \mathrm{~cm}$ in the control group); these children, in whom an effect of the programme on growth was found, still on average had HAZ below -1 SD at the end of 
the study. In another study, the Oportunidades programme was evaluated after 2 years of operation in urban areas $^{(4)}$. In this evaluation, children in households who were enrolled in the programme were compared at baseline and after a 2-year period with children eligible for the programme but who were not enrolled. No difference in growth of children aged 6-24 months who were included in the Oportunidades programme was found, in comparison with the control group. A significant effect of the programme was seen only in children who were $<6$ months of age at baseline, who grew $1.5 \mathrm{~cm}$ more than the children who were not enrolled in the programme. A longitudinal study of 300 children between 6 and 23 months of age, living in urban communities, found no difference in growth between the children who were enrolled in the Oportunidades programme and those who were not ${ }^{(6)}$. Neufeld et al. ${ }^{(7)}$ studied the effect of the programme on the growth of 150 children between 6 and 23 months of age in an urban area and compared them with 150 children from families with similar characteristics but who were not part of the programme; analysis was performed using data from previous studies in which children were evaluated at baseline and after 2 years of being enrolled in the Oportunidades programme. Data were analysed in three different ways: first, the authors considered the data of those families that reported to be in the programme; second, the data of the families that were officially registered in the programme were taken into consideration; and third, the authors crossed the data of the families reported to be in the programme and those that were registered. Similar to our study, no effect of the programme was found on the growth of children who were part of the programme either by self-report or by being officially registered. Only when data on self-report and registration were crossed was a significant increase of $0.86 \mathrm{~cm}$ on the growth of children aged $<24$ months compared with the control group observed. Children in our study and the children included in the studies in which the effect of the programme on growth has been evaluated $^{(3,4,6,7)}$ had similar deficit in growth at baseline; therefore, our study and previous evaluations show that neither the supplement nor the whole programme brings additional benefits on the growth of children aged 12-24 months.

All experimental groups had higher $\mathrm{Hb}$ concentrations at the end of the study, including the PL group, but still remained anaemic. This increase in $\mathrm{Hb}$ in the PL group has been previously observed in other studies carried out by our group ${ }^{(15,16)}$. It is probable that other factors such as diet are influencing $\mathrm{Hb}$ concentration in these children. An improvement in their diets may have caused the increase in $\mathrm{Hb}$ concentrations observed in the three groups; however, this cannot be confirmed since children's food intake during the trial was not recorded.

No differences in $\mathrm{Hb}$ concentration or in the prevalence of anaemia were found among groups after 6 months; changes in $\mathrm{Hb}$ and anaemia of the OFS and PM groups were similar to those of the control group. Rivera et al. ${ }^{(3)}$ found a significantly lower prevalence of anaemia among children aged 6-12 months who had participated in the Oportunidades programme for 1 year $(44 \cdot 3 \%)$, compared with children who did not $(54.9 \% ; P<0.05)$. In the study by Neufeld et $a l^{(6)}$, children aged 6-23 months included in the Oportunidades programme had higher $\mathrm{Hb}$ concentration and lower prevalence of anaemia than children not included in the programme; in that study, no effect was seen on older children. The different results in the prevalence of anaemia compared with our study suggest that other components of the programme, such as health surveillance, economic benefits or education, are also important to improve $\mathrm{Hb}$.

We found no improvement in the number of episodes or duration (d) of gastrointestinal or respiratory diseases after consuming OFS for 6 months. To our knowledge, there is only one report that evaluated the effect of the Oportunidades programme on morbidity. In that study, Gutierrez et $a l .{ }^{(17)}$ estimated the impact of the Oportunidades programme on morbidity using the methodology known as paired-by-propensity score, in which they compared data of each family or member of the family that was included in the programme for $3 \cdot 5-5 \cdot 5$ years with one or more families that were not included at the time of evaluation. They estimated a $20 \%$ decrease in the days of sickness among children aged $0-5$ years. This decrease represents a reduction of two sick days/year per family among children in that age group. Since we did not find an effect of the supplement on morbidity in the present study, it might be that other components of the programme, especially health surveillance and economic improvement, are more important than supplementation to reduce morbidity.

Results of our study show no effect of the nutritional supplement on cognitive function; the three groups improved their motor and mental functions, but they had similar improvement in all tests at the end of the study. Our results are similar to those of Neufeld et $a l^{(6)}$; in their longitudinal study, they reported no differences in rates of language acquisition among children aged 6-23 months. In addition, Gertler and Fernald ${ }^{(18)}$ evaluated children exposed to the programme for 3-6 years; they measured memory, language acquisition, motor development and social behaviour and compared the measurements with a group of children of the same age who had not been part of the programme. The evaluation found no impact of the programme on cognitive development of children who have been exposed to the programme for 3-6 years.

In the present study, we supplemented children for 6 months; we do not know whether supplementation for a longer period will produce different results in any of the functional outcomes analysed. Moreover, we only included children from 12 to 24 months of age; therefore, the implications of our study should be limited to children in 
this age range. As discussed, other studies have shown an effect of the programme, not of the supplement, on growth of younger children ${ }^{(3,4)}$. The fact that in our study the children in the PL control group were followed up for 6 months and received attention from our fieldworkers on a daily basis could explain why these children improved in growth and $\mathrm{Hb}$, just as the OFS and PM groups.

In conclusion, supplementation for 6 months with OFS in children aged 12-24 months does not produce additional benefits, compared with treatment with an empty energy PL, on growth, anaemia, morbidity and cognitive performance. The benefits of the Oportunidades programme on anaemia and morbidity that have been reported in previous studies in children aged $<24$ months should be attributed to other components of the programme, not to the supplementation per se. Given the results of the present study and considering the high cost of supplementation, we suggest that the supplementation strategy as part of the Oportunidades programme in children of this age be carefully revised.

\section{Acknowledgements}

The present study was partially funded by the National Council of Science and Technology, CONACYT Study Code 19980202010. The authors have no conflict of interest. J.L.R. contributed to the study design, study supervision, data interpretation and writing of the manuscript; P.L. participated in the study design, coordinated the field work and supervised the data collection; O.P.G. contributed to the study design, data interpretation and writing of the manuscript; J.A. was responsible for the cognitive function tests; C.A. coordinated the field research.

\section{References}

1. Secretaría de Desarrollo Social (2006). Programa Oportunidades. Reglas de Operación 2006. México: Secretaría de Desarrollo Social.

2. Rosado JL, Rivera J, López G et al. (1999) Desarrollo y evaluación de suplementos alimenticios para el Programa de Educación, Salud y Alimentación. Salud Publica Mex 41, 141-158

3. Rivera JA, Sotres-Alvarez D, Habicht JP et al. (2004) Impact of the Mexican program for education, health, and nutrition (Progresa) on rates of growth and anemia in infants and young children: a randomized effectiveness study. JAMA 291, 2563-2570.

4. Leroy JL, Garcia-Guerra A, Garcia R et al. (2008) The Oportunidades program increases the linear growth of children enrolled at young ages in urban Mexico. $J$ Nutr 138, 793-798.
5. Neufeld L, Sotres-Alvarez D, Gertler P et al. (2004) Impacto de Oportunidades en el crecimiento y estado nutricional de niños en zonas rurales. In Evaluación externa de impacto del Programa Oportunidades 2004. Tomo III. Alimentación, pp. 15-50 [B Hernández and M Hernández-Ávila, editors]. Cuernavaca, México: Instituto Nacional de Salud Pública.

6. Neufeld L, Sotres-Alvarez D, García-Feregrino $\mathrm{R}$ et al. (2004) Estudio comparativo sobre el estado nutricional y la adquisición de lenguaje entre niños de localidades urbanas con y sin Oportunidades. In Evaluación externa de impacto del Programa Oportunidades 2004. Tomo III. Alimentación, pp. 87-116 [B Hernández and M HernándezÁvila, editors]. Cuernavaca, México: Instituto Nacional de Salud Pública.

7. Neufeld LM, García-Guerra A, Leroy LJ et al. (2006) Impacto del Programa Oportunidades en nutrición y alimentación en zonas urbanas de México. In Evaluación externa de impacto del Programa Oportunidades 2006. Tomo II. Alimentación, pp. 47-71 [B Hernández-Prado and M Hernández Avila, editors]. Cuernavaca, México: Instituto Nacional de Salud Pública.

8. Rosado JL, Cassis L, Solano L et al. (2005) Nutrient addition to corn masa flour: effect on corn flour stability, nutrient loss, and acceptability of fortified corn tortillas. Food Nutr Bull 26, 266-272.

9. Rosado JL, López P, Muñoz E et al. (1997) Zinc supplementation reduced morbidity, but neither zinc nor iron supplementation affected growth or body composition of Mexican preschoolers. Am J Clin Nutr 65, 13-19.

10. Lohman TG, Roche AF \& Martorell R (1988) Standardization Reference Manual. Champaign, IL: Human Kinetics.

11. Dirren H, Logman HGM, Barclay DV et al. (1994) Altitude correction for hemoglobin. Eur J Clin Nutr 48, 625-632.

12. Gibson RS (1990) Principles of Nutritional Assessment. New York, NY: Oxford University Press, Inc.

13. Schnaas L (1998) Escala de Desarrollo Infantil de Bayley, 2nd ed. México: Instituto Nacional de Perinatología.

14. World Health Organization (2006) Child Growth Standards. Geneva: WHO

15. Allen L, Rosado JL, Casterline JE et al. (2000) Lack of hemoglobin response to iron supplementation in anemic Mexican preschoolers with multiple micronutrient deficiencies. Am J Clin Nutr 71, 1485-1494.

16. García OP, Díaz M, Rosado JL et al. (2003) Ascorbic acid from lime juice does not improve the iron status of irondeficient women in rural Mexico. Am J Clin Nutr 78, 267-273.

17. Gutiérrez JP, Bautista S, Gertler P et al. (2005) Impacto de Oportunidades en la morbilidad y el estado de salud de la población beneficiaria y en la utilización de los servicios de salud. Resultados de corto plazo en zonas urbanas y de mediano plazo en zonas rurales. In Evaluación externa de impacto del Programa Oportunidades 2004, pp. 19-69 [B Hernández and M HernándezÁvila, editors]. Cuernavaca, México: Instituto Nacional de Salud Pública.

18. Gertler PJ \& Fernald LC (2004) Impacto de mediano plazo del Programa Oportunidades sobre el desarrollo infantil en áreas rurales. In Evaluación externa de impacto del Programa Oportunidades 2004. Tomo III. Alimentación, pp. 51-85 [B Hernández and M Hernández-Ávila editors]. Cuernavaca, México: Instituto Nacional de Salud Pública. 